\title{
New insights into the role of non-coding RNAs as transcriptional targets of p53
}

\author{
Cristina-Sorina Catana ${ }^{1}$, Diana Gulei ${ }^{2}$, Ioana Berindan-Neagoe ${ }^{2,3,4 *}$
}

\author{
${ }^{1}$ Department of Biochemistry, Faculty of Medicine, "Iuliu Hațieganu" University of Medicine and Pharmacy, \\ Cluj-Napoca, Romania \\ ${ }^{2}$ Research Center for Advanced Medicine, Medfuture, "Iuliu Hațieganu" University of Medicine and Pharmacy, \\ Cluj-Napoca, Romania \\ ${ }^{3}$ Research Center for Functional Genomics Biomedicine and Translational Medicine, \\ "Iuliu Hațieganu" University of Medicine and Pharmacy, Cluj-Napoca, Romania \\ ${ }^{4}$ Department of Functional Genomics, Proteomics and Experimental Pathology, \\ The Oncology Institute Prof. Dr. Ion Chiricuta, Cluj-Napoca, Romania
}

(Received 26 March, 2017; accepted 8 May, 2017)

\begin{abstract}
P53 classifies as one of the main tumor suppressor gene and the identification of its direct transcriptional targets such as certain non-coding RNAs (ncRNAs) is important for understanding the development and progression of cancer. Multiple ncRNAs are targeting $\mathbf{p} 53$ and are involved in many cellular processes such as cell cycle arrest, metabolism, apoptosis, autophagy and feedback mechanisms. Also, various ncRNAs were found to modulate p53-dependent gene regulation. These include microRNAs such as $m i R-660, m i R-486, m i R-34$ and lncRNAs such as nuclear enriched abundant transcript 1 (NEAT1), which contribute to the tumor-suppressor function of the p53 protein. Long intergenic non-coding RNA, LincRNA-p21, has been proclaimed to promote apoptosis while other p53-regulated lncRNAs including PANDA and Pint antagonize p53 activity by limiting the activation of proapoptotic genes. Taking into account the activity of the proapoptotic transcription factor $\mathrm{p} 53$, new conclusions point to a new concept of cellular quality control since ncRNAs-based deregulation in cancer functions in the absence of $\mathrm{p} 53$ coding sequence mutations.
\end{abstract}

Keywords: long non-coding RNAs; p53; apoptosis; lincRNA-p21

\section{INTRODUCTION}

Discovered by mistake, $\mathbf{p} 53$ is nowadays the main tumor suppressor molecule with numerous mechanisms related to cancer inhibition. Known in the scientific literature as 'the guardian of the genome', the gene and the protein generate more than 80000 entries in PubMed in connection with various types of cancers (1-3). This strong relationship between p53 and malignant pathologies is mainly caused by the mutated forms of the gene, which are altered in more than half of all cancers $(4,5)$. The activation of the protein is stimulated by stress alarms of various origins such as the activation of oncogenes, the acquisition of DNA damage and hypoxia. The perception of these stress signals results in the arrest of the cell cycle in the associated checkpoints in order to permit DNA corrections, or, if the damage is too extensive, the cell undergoes programmed cell death (6). The main role of p53 as a carcinogenic inhibitor consists in the regulation at the transcriptional level of the target genes that control various cellular processes including programmed cell death, DNA repair mechanisms, autophagy, metabolism, cell cycle control and thus genetic integrity (7-10).

The elements targeted by $\mathrm{p} 53$, a cancer suppressor interacting with numerous target genes, were presented through meta-analysis statistics, which showed that the target genes characterized by high confidence are involved in numerous feedback loops at cellular level such as cell cycle arrest, metabolism, and mRNA translation. At the same time, a series of mechanisms were associated with the modulatory aspects of gene control in response to p53 (11-13). To our knowledge, research studies revealed that $\mathrm{p} 53$ can act as a catalyst of transcription. Moreover, gene down-regulation by $\mathrm{p} 53$ is indirect and

*Corresponding author (E-mail: ioana.neagoe@umfcluj.ro) 
depends on p21 expression. Considering the importance of p53 as an activator of transcription, new ideas point to a straightforward concept of cellular quality control $(12,13)$.

The stimulation of $\mathrm{p} 53$ is induced by oncogenic activation, stress at the ribosomal level or hypoxia and DNA damage, which initiate a series of $\mathrm{p} 53$ vibrations ultimately leading to the activation of target genes $(6,13)$. The p53 transcription factor needs two transactivation domains in order for the controlling action on gene expression to take place while the transactivation of target genes relies on the interconnected interaction between the p53 proteins at DNA response elements (REs) (12, 14-16).

The kinetics of P53-activating target genes changes through stimulus- and promoter-specific enrollment of transcription induction ingredients and polymerase II enzymes (17-20). However, evidence based on genome-wide profiling does not support the promoter-specific actions of the protein, thus suggesting an unsophisticated p53 binding (12).

Non-coding RNAs (ncRNAs) comprise a class of sequences that are able to regulate gene expression without undergoing translational processes (20).

\section{p53-regulated lncRNAs}

Pint long intergenic non-coding RNAs (lincRNA) links the $\mathrm{p} 53$ mechanism with epigenetic silencing through the Polycomb repressive complex 2. The activation of lncRNA NEAT1 that is a direct target (transcription level) of $\mathrm{p} 53$ enforces the tumor-suppressor mechanisms of this protein $(30,31)$. Presenilin (PS)-2, an essential gene associated with familial Alzheimer's disease (AD) could induce apoptosis through the p53/miR-34a axis (32). PANDA lincRNA correlates with nuclear transcription factor Y subunit alpha (NF-YA) and blocks it's binding to promoters of apoptosis-related genes, thus suppressing apoptosis in normal human fibroblasts (33). However, results relying on different experimental models have limited applicability. For example, studies that modulated the expression of lincRNA-p21 or miR-34 (loss of function or overexpression strategies) hardly overlap with those that adopted knockout mice.

There is a lack of consensus regarding knock-out experimental models as far as the effects of LincRNA-p21 deficiency are concerned. Some studied showed that LincRNA-p21 removal declined p21 expression and promoted the proliferation of mouse embryonic fibroblasts (MEFs), while in other experiments there was no decline in $\mathrm{p} 21$ protein level following the loss of function of LincRNA-p21. A possible answer to this dichotomy is that a complete loss of linc-RNA-p21 (as achieved by genetic deletion) is mandatory in order to deregulate the expression of $\mathrm{p} 21$. Therefore, future studies on lncRNAs and p21 interaction need to resolve this issue (34-38) (Table 1).
Based on the description of mouse lncRNAs directly induced by $\mathrm{p} 53$, LincRNA-p 21 has been proposed to promote apoptosis, while other p53-regulated lncRNAs, including PANDA and Pint, antagonize p53 activity by limiting the activation of proapoptotic genes $(33,37)$ (Fig. 1). Originally discovered in mice (mLincRNA-p21), LincRNA-p21 is also present in humans (hmLincRNA-p21). However, the homology between these two lncRNAs is limited to a short transcript region of 130nt at 5'end including the binding site for the hnRNPk protein and the $\mathrm{p} 53$-response element. Moreover, many $\mathrm{m}$ LincRNA-p21 target genes validated in mice are not controlled by $\mathrm{p} 53$ in humans while in human diseases $\mathrm{h} L i n c R N A-p 21$ is a specific target of NEAT1, which modulates p53-induced tumor-suppressor function and transactivation $(28,39,40)$. Tests of functional screening and expression profiling revealed that LincRNA-p21 also interacts with cellular reprogramming, conducting towards inhibition of the process. Exceptionally, LincRNA-p21, which is transcribed as a result of $\mathrm{p} 53$ stimulation, does not determine cell senescence and apoptosis in the reprogramming process. Alternately, LincRNA-p 21 acts simultaneously with the histone $\mathrm{H} 3$ lysine 9 (H3K9) methyltransferase SETDB1, which is recurrently overexpressed in melanoma. The conservation DNA methyltransferase DNMT1 determined by the RNA-binding heterogeneous nuclear ribonucleoprotein K (HNRNP-K) interacts directly and binds to the promoter regions that are silenced in tumor cells $(28,39-41)$.

Consequently, LincRNA-p21 impairs reprogramming by promoting $\mathrm{CpG}$ methylation or $\mathrm{H} 3 \mathrm{~K} 9 \mathrm{me} 3$ at the promoters of pluripotency genes. Thus, IncRNAs underline a hidden connection between heterochromatin regulation and p53 as a transcription factor (42) (Fig. 1).

\section{p53-regulated miRNAs}

Certain ncRNAs were found to regulate p53-dependent gene control $(21,22)$. These include microRNAs such as miR-660 and miR-486, which are p53-dependent, and long non-coding RNAs (lncRNAs) such as TUG1 (taurine upregulated gene 1), the p53/TUG1/polycomb repressive complex-2 (PRC2)/homeodomain-containing protein (HOXB7) interaction as targets for the diagnosis and treatment of non-small cell lung carcinoma (NSCLC), miR-34, LincRNA-p21, p53 induced non-coding transcript (Pint) and $\mathrm{p} 21$-associated ncRNA DNA damage-activated (PANDA) (24-30) (Table 1).

\section{THE DUAL NATURE OF p53 REGULATION IN CANCER}

The crosstalk between the p 53 network and miRNAs is important in cancers. Firstly, miRNAs can modulate the activity of p53 by various mechanisms. Moreover, the removal of mutated p53 (which represses certain 


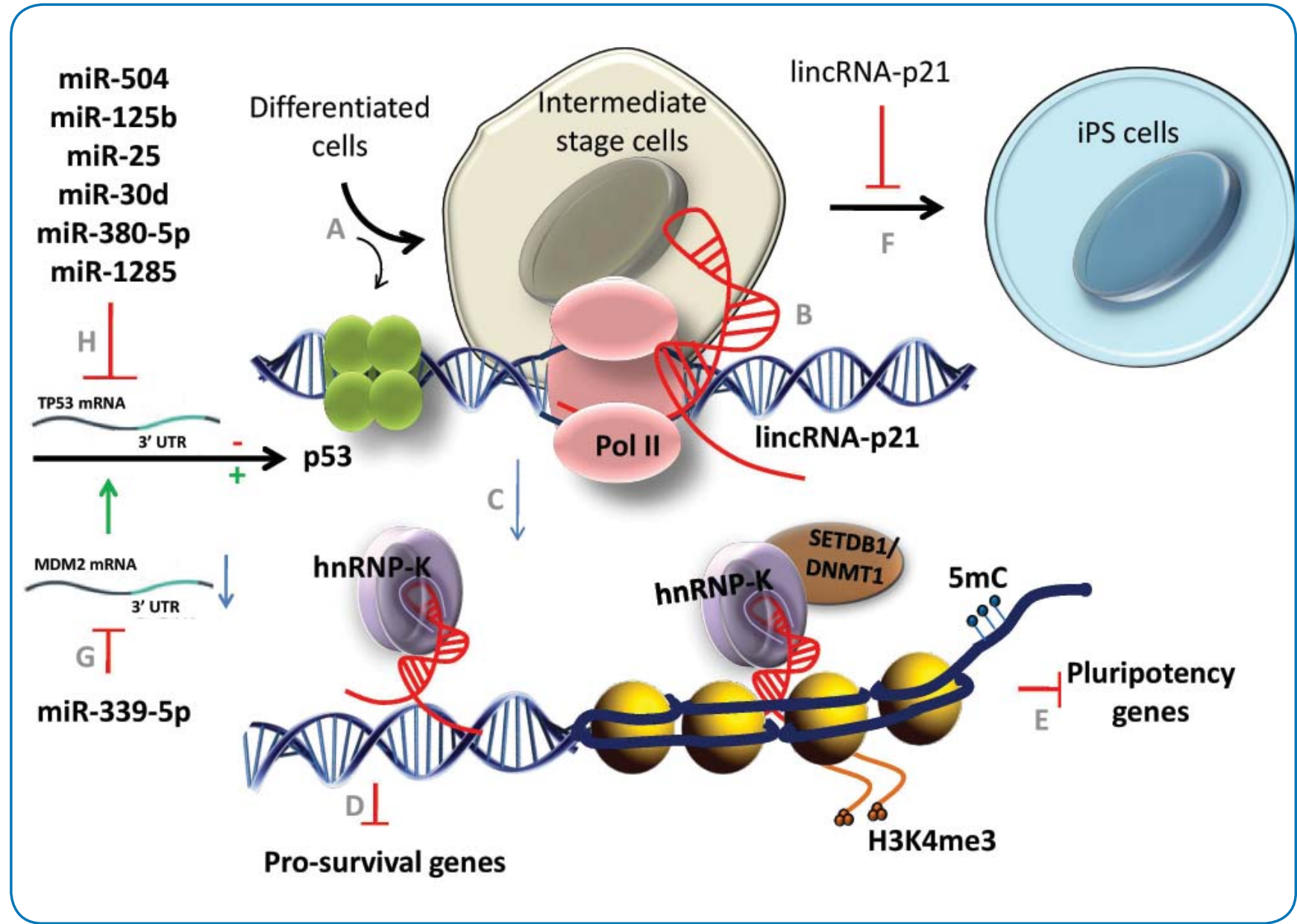

Fig. 1. - LincRNA-p21 and miRNAs impair cellular reprogramming. p53 is maintaining the intermediate stage of cells in terms of cells reprogramming through lincRNA-p21. (A) The transformation of differentiated cells into intermediate stage cells promotes the expression of TP53 and results in an increased amount of p53. (B) The protein is able to stimulate the transcription of lincRNA-p21, which further (C) combines with hnRNP-K, directing together the inhibition of pro-survival gene expression (D). The intermediate stage may also be maintained through epigenetic modification mediated by lincRNA-p21 instead of through the apoptosis mechanism. (E). This sequence indirectly combines with SETDB1/DNMT1 and binds the promoter of pluripotency genes, thus highlighting histone modification via $\mathrm{H} 4 \mathrm{~K} 4 \mathrm{me} 3$ and DNA methylation. In this way, the translation of the target genes is impaired and the transition towards iPSC is inhibited (F). On the one hand, miR-339-5p activates p53, thus acting as a tumor suppressor through the direct binding of 3'-UTR of MDM2 mRNA, where MDM2 inhibits the level of p53 (G). On the other hand, microRNAs interfere with p53 expression by interacting with the 3'UTR of p53 mRNA in a sequence-specific manner $(\mathrm{H})$.

Abbreviations: iPSC - induced pluripotent stem cells; H3K9 - histone H3 lysine 9;

SETDB1 - Histone-lysine N- methyltransferase; HNRNP-K - heterogeneous nuclear ribonucleoprotein K;

DNMT1 - DNA methyltransferase; H3K9me3 - histone demethylase.

miRNAs activated by wild-type p53) interferes with cell senescence and apoptosis, thus having a key role in tumor progression and invasion. Therefore, multiple myeloma is an incurable blood cancer characterized by an overproduction of immunoglobulin. Since p53 is hardly mutated in this type of cancer, multiple myeloma is a reliable model for the study of microRNA overexpression as a complementary mechanism of p53 suppression (20, 43).

Over the past seven years, research has identified 11 microRNAs (miRNAs) that negatively control p53 expression by directly targeting the 3' untranslated region (3' UTR) (Fig. 1). These miRNAs are able to suppress the expression of the tumor suppressor genes and implicitly promote pro-carcinogenic mechanisms. Examples include miR-25 and miR-30d, which are both capable to exert regulatory actions in terms of apoptosis, senescence and cell cycle arrest by inhibiting p53 stress-response pathways (44).

Following a similar direct binding mechanism, miR-125b is also able to influence the fate of the p53 transcript, as it exerts inhibitory action on protein levels in different human cells like neuroblastoma and lung fibroblast cells, thus generating a resistant phenotype that does not respond to cell death signals. Moreover, this inhibitory action is further translated in terms of 
Table 1. Example of non-coding RNAs modulating the p53-dependent mechanism

\begin{tabular}{|c|c|c|c|}
\hline ncRNAs & Genetic role in cancer & Effects on p53 & Ref \\
\hline$m i R-34$ & $\begin{array}{l}\text { Anti-tumor effect } \\
\text { p53/miR-34a/SIRT1 causes Quercetin-Induced } \\
\text { Apoptosis through positive feedback loop }\end{array}$ & Exhibits wild-type p53 in HepG 2 cells & 55 \\
\hline $\begin{array}{l}\text { miR-660- } \\
\text { p53-miR-486 } \\
\text { network }\end{array}$ & $\begin{array}{l}\text { Synergistic effect in lung cancer treatment } \\
\text { Cell-cycle arrest or cell death } \\
\text { Escape of immune surveillance in malignant } \\
\text { scenarios } \\
\text { Expression of other miRNAs in NSCLC including } \\
\text { mir-181, mir-184, and mir-148 }\end{array}$ & $\begin{array}{l}\text { Exhibits wild-type p53 in NSCLC } \\
\text { Regulates PDL1 for NSCLC }\end{array}$ & 56 \\
\hline$m i R-339-5 p$ & $\begin{array}{l}\text { Tumor suppression through MDM2 (inhibitor } \\
\text { of p53 transcriptional activation)/p53 negative } \\
\text { feedback loop }\end{array}$ & $\begin{array}{l}\text { Activates p53 functions in cellular senescence } \\
\text { and apoptosis in CRC, lung and breast cancers }\end{array}$ & 54 \\
\hline$m i R-25$ & $\begin{array}{l}\text { The regulation process mediated by } m i R-25 \\
\text { impairs cell cycle arrest, apoptosis and senescence } \\
\text { in multiple myeloma }\end{array}$ & $\begin{array}{l}\text { Inhibits the effect of p } 53 \text { on cellular } \\
\text { senescence in HCT } 116 \text { cells }\end{array}$ & 44 \\
\hline $\operatorname{miR}-30 d$ & $\begin{array}{l}\text { The regulation process mediated by miR-30d } \\
\text { impairs cell cycle arrest, apoptosis and senescence } \\
\text { in multiple myeloma }\end{array}$ & Blocks the p53 stress-response pathway & 44,57 \\
\hline $\operatorname{miR}-125 b$ & $\begin{array}{l}\text { Involved in the promotion of neuroblastoma } \\
\text { cells and lung fibroblasts in vitro by impairing } \\
\text { programmed cell death; } \\
\text { Increases the sensitivity of osteosarcoma cells to } \\
\text { cisplatin; } \\
\text { Reduced levels in HCC cells }\end{array}$ & $\begin{array}{l}\text { Suppresses p53 actions in human lung } \\
\text { fibroblast cells, neuroblastoma and } \\
\text { osteosarcoma cells; } \\
\text { Upregulates p53-cancer-associated pathways } \\
\text { involved in cell cycle control, protein } \\
\text { degradation, adhesion and expression related } \\
\text { mechanisms (transcription and translation) }\end{array}$ & $\begin{array}{l}45, \\
46 \\
58\end{array}$ \\
\hline$m i R-504$ & $\begin{array}{l}\text { Negative regulator of p53-mediated apoptosis, } \\
\text { p } 53 \text { transcriptional activity and cell-cycle arrest in } \\
\text { response to stress }\end{array}$ & $\begin{array}{l}\text { Suppresses the p } 53 \text { target } \\
\text { Inhibits p } 53 \text { protein amounts directly } \\
\text { correlated with apoptotic levels and cell cycle } \\
\text { arrest }\end{array}$ & 47,59 \\
\hline$m i R-380-5 p$ & $\begin{array}{l}\text { Apoptosis impairment } \\
\text { Increased tumor related physical parameters (e.g., } \\
\text { size) }\end{array}$ & Down-regulates the p53 target & $\begin{array}{l}48, \\
57,59\end{array}$ \\
\hline $\operatorname{miR}-92$ & Promotes proliferation & $\begin{array}{l}\text { Inhibits p53 protein amounts directly } \\
\text { correlated with apoptotic levels and cell cycle } \\
\text { arrest }\end{array}$ & 49 \\
\hline$m i R-141$ & $\begin{array}{l}\text { Mediates cell survival under stress ondition in } \\
\text { ovarian cancer cells } \\
\text {-Inducing cancer metastasis }\end{array}$ & Down-regulates the p53 target & 49,60 \\
\hline$m i R-1285$ & $\begin{array}{l}\text { Promotes tumor progression and etastasis, cell } \\
\text { differentiation }\end{array}$ & Mutual inhibition of p53-miRNA & $\begin{array}{l}50 \\
51,61\end{array}$ \\
\hline$m i R-200 a$ & $\begin{array}{l}\text { Promotes malignant cell transformation and } \\
\text { metastasis }\end{array}$ & Mutual inhibition of p53-miRNA & 52,61 \\
\hline$m i R-16$ & $\begin{array}{l}\text { Promotes tumor progression and metastasis, cell } \\
\text { differentiation }\end{array}$ & Mutual inhibition of p53-miRNA & $\begin{array}{l}20, \\
53,61\end{array}$ \\
\hline $\operatorname{miR}-15$ & $\begin{array}{l}\text { Promotes tumor progression and metastasis, cell } \\
\text { differentiation }\end{array}$ & Mutual inhibition of p53-miRNA & $\begin{array}{l}20, \\
53,61\end{array}$ \\
\hline $\operatorname{lncRNA-NEAT1}$ & Stimulates cancer cell growth & Knockdown of p53-induced apoptosis & 31 \\
\hline $\operatorname{lincRNA-p21}$ & Blocks cell senescence and apoptosis & not controlled by p53 & 12,42 \\
\hline IncRNA-PANDA & Blocks cell senescence and apoptosis & not controlled by p53 & 12 \\
\hline $\operatorname{lncRNA-PINT}$ & Blocks cell senescence and apoptosis & not controlled by p53 & 12 \\
\hline
\end{tabular}

Abbreviations: ncRNA - non-coding RNA; miR - microRNA; lncRNA-long non-coding RNA; lincRNA - long intergenic non-protein Coding RNA; NEAT1/VINC - Nuclear Enriched Abundant Transcript 1/Virus Inducible NonCoding RNA; lincRNA - long intergenic non-coding RNAs; PINT - P53 Induced Transcript; PANDA - p21-associated ncRNA DNA damage activated; SIRT1 - sirtuin 1; PDL1 - Programmed Death 1 Ligand; NSCLC - non-small cell lung carcinoma; MDM2- E3 ubiquitin ligase or mouse double minute 2 homolog (inhibitor of p53 transcriptional activation) 
apoptosis levels under conditions of stress or development (45). MiR-125b overexpression promotes the cisplatin chemosensitivity of osteosarcoma cell lines through the modulation of Bcl-2 (46).

MiR-504 negatively regulates the $\mathrm{p} 53$ protein by decreasing its expression and functional roles in cells, including p53 as a transcription activator, apoptosis and also cell-cycle arrest. Consequently, miR-504 positively regulates cell tumorigenicity in vivo (47).

Decreased levels of miR-380-5p in neuroblastoma or embryonic stem cells cause the activation of p53 and apoptosis. Moreover, in in vivo preclinical models of neuroblastoma, the delivery of a miR-380-5p antagonist inhibited tumor size by impairing cell survival under stress $(20,48)$.

MiR-92 and miR-141 are important determinants of pluripotency and reprogramming by inferring with embryonic states, thus inducing pluripotent stem cells (49). P53 can also silence miR-1285, which increases p53 expression $(50,51)$.

MiR-200a has an oncogenic role by promoting malignant cell transformation and metastasis mediated by the mutual inhibition of p53 (52). Recent research showed the existence of a molecular circuitry in which miR-16, miR-15 and p53 specific targets cooperate in order to promote tumor invasiveness through stromal and cancer cells in two way communication $(20,53)$.

In addition, recent research revealed that miR-339-5p plays an important role in activating the $\mathrm{p} 53$ function in tumor suppression through directly binding to the 3'-UTR of MDM2 (E3 ubiquitin ligase or mouse double minute 2 homolog, an inhibitor of p53 transcriptional activation) mRNA. This miR diminishes MDM2 protein levels, thus increasing cellular p53 protein load, which induces the expansion of p53 actions such as the inhibition of cell migration, the stimulation of senescence and apoptosis processes (54).

\section{REFERENCES}

1. Vogelstein B, Lane D, Levine AJ, Surfing the p53 network, Nature, 408, 307-310 (2000).

2. Lin T, Lin Y, $p 53$ switches off pluripotency on differentiation, Stem Cell Res. Ther., 8, 44 (2017).

3. Irimie AI, Braicu C, Pileczki V, Petrushev B, Soritau O, Campian RS, Berindan-Neagoe I, Knocking down of $p 53$ triggers apoptosis and autophagy, concomitantly with inhibition of migration on SSC-4 oral squamous carcinoma cells, Mol. Cell. Biochem., 419, 75-82 (2016).

4. Berindan-Neagoe I, Balacescu O, Burz C, Braicu C, Balacescu L, Tudoran $\mathrm{O}$, Cristea $\mathrm{V}$, Irimie $\mathrm{A}$, $p 53$ gene therapy using $R N A$ interference, J. BUON, 14 Suppl 1, S51-9 (2009).

5. Treviño V, Martínez-Ledesma E, Tamez-Peña J, Identification of outcome-related driver mutations in cancer using conditional co-occurrence distributions, Sci. Rep., 7, 43350 (2017).

6. Horn HF, Vousden KH, Coping with stress: multiple ways to

\section{CONCLUSION}

In this review we established links between ncRNAs and the p53 network - a well known guardian of the genome, which is especially important during the stress response activated in all types of cancers. The endogenous LincRNA-p21 functions as a key regulatory checkpoint under stress conditions and could serve as a valuable therapeutic target for tumors.

miRNAs switching from repression to activation act as cellular micro-hormones if the level of the target mRNA is below a stress threshold. They can also act as fine-tuners if the target mRNA level is over expressed.

In conclusion, the interaction between non-coding RNA-based regulatory mechanisms and the $\mathrm{p} 53$ system is obvious and has a crucial role in maintaining the quality control of cells.

Author contributions: Professor Ioana Berindan-Neagoe suggested the topic and designed the study. She was also responsible for the final form of the manuscript by carefully and critically reviewing its last version. Dr. Cristina-Sorina Catana wrote the manuscript after reviewing and summarizing the most recent literature data available. Diana Gulei contributed with the Figure and explanations.

Acknowledgments: This work was supported by a PhD fellowship (PCD 2016), "Genome modifying and editing mechanisms", and by a POC grant Nr.35/01.09.2016, ID 37_796, entitled "Clinical and economical impact of personalized targeted anti-microRNA therapies in reconverting lung cancer chemoresistance" - CANTEMIR.

The authors have nothing to disclose.

activate p53, Oncogene, 26, 1306-1316 (2007).

7. Braicu C, Pileczki V, Irimie A, Berindan-Neagoe I, $p 53$ siRNA therapy reduces cell proliferation, migration and induces apoptosis in triple negative breast cancer cells, Mol. Cell. Biochem., 381, 61-68 (2013).

8. Berindan-Neagoe I, Braicu C, Irimie A, Combining the chemotherapeutic effects of epigallocatechin 3-gallate with siRNA-mediated $p 53$ knock-down results in synergic pro-apoptotic effects, Int. J. Nanomedicine, 7, 6035-6047 (2012).

9. Riley T, Sontag E, Chen P, Levine A, Transcriptional control of human p53-regulated genes, Nat. Rev. Mol. Cell Biol., 9, 402-412 (2008).

10. Vogiatzi F, Brandt DT, Schneikert J, Fuchs J, Grikscheit K, Wanzel M, et al., Mutant $p 53$ promotes tumor progression and metastasis by the endoplasmic reticulum UDPase ENTPD5, Proc. Natl. Acad. Sci. U.S.A., 113, E8433-E8442 (2016). 
11. Braicu C, Pileczki V, Pop L, Cojocneanu Petric R, Chira S, Pointiere E, Achimas-Cadariu P, Berindan-Neagoe I, Dual targeted therapy with $p 53$ siRNA and Epigallocatechingallate in a triple negative breast cancer cell model,

PLoS One, 10, e0120936 (2015)

12. Fisher M, Census and evaluation of $p 53$ target genes, Oncogene, [Epub ahead of print] (2017).

13. Luo Q, Beaver JM, Liu Y, Zhang Z, Dynamics of $\mathrm{p} 53$ : A Master Decider of Cell Fate, Genes (Basel), 8, E66 (2017).

14. Napoli M, Flores ER, The $p 53$ family orchestrates the regulation of metabolism: physiological regulation and implications for cancer therapy, Br. J. Cancer, 116, 149-155 (2017).

15. Schlereth K, Heyl C, Krampitz AM, Mernberger M, Finkernagel F, Scharfe M, et al., Characterization of the $p 53$ cistrome-DNA binding cooperativity dissects $p 53$ 's tumor suppressor functions, PLoS Genet., 9, e1003726 (2013).

16. Enthart A, Klein C, Dehner A, Coles M, Gemmecker G, Kessler $\mathrm{H}$, et al., Solution structure and binding specificity of the p63 DNA binding domain, Sci. Rep., 6, 26707 (2016).

17. Espinosa JM, Verdun RE, Emerson BM, p53 functions through stress-and promoter-specific recruitment of transcription initiation components before and after DNA damage,

Mol. Cell., 12, 1015-1027 (2003).

18. Marbach-Bar N, Bahat A, Ashkenazi S, Golan-Mashiach M, Haimov O, Wu SY, et al., DTIE, a novel core promoter element that directs start site selection in TATA-less genes, Nucleic Acids Res., 44, 1080-1094 (2016).

19. Lauberth SM, Nakayama T, Wu X, Ferris AL, Tang Z, Hughes $\mathrm{SH}$, et al., H3K4me3 interactions with TAF3 regulate preinitiation complex assembly and selective gene activation,

Cell, 152, 1021-1036 (2013).

20. Deng Q, Becker L, Xiaodong M, Zhong X, Young K, Ramos K, et al., The dichotomy of $p 53$ regulation by noncoding $R N A s$, J. Mol. Cell Biol., 6, 197-205 (2014).

21. Mukhadi S, Hull R, Mbita Z, Dlamini Z, The Role of MicroRNAs in Kidney Disease, Non-Coding RNA, 1, 192-222 (2015).

22. Schou JV, Johansen JS, Nielsen D, Rossi S, Circulating microRNAs as Prognostic and Predictive Biomarkers in Patients with Colorectal Cancer, Non-Coding RNA, 2, 5 (2016).

23. Borzi C, Calzolari L, Centonze G, Milione M, Sozzi G, Fortunato O, mir-660-p53-mir-486 Network: A New Key Regulatory Pathway in Lung Tumorigenesis,

Int. J. Mol. Sci., 18, E222 (2017).

24. Grossi E, Sánchez Y, Huarte M, Expanding the p53 regulatory network: LncRNAs take up the challenge,

Biochim. Biophys. Acta, 1859, 200-208 (2016).

25. Khalil AM, Guttman M, Huarte M, Garber M, Raj A, Rivea Morales D, et al., Many human large intergenic noncoding RNAs associate with chromatin-modifying complexes and affect gene expression, Proc. Natl. Acad. Sci. USA,

106, 11667-11672 (2009).

26. Zhang E, Yin D, Sun M, Kong R, Liu X, You L, et al., p53-regulated long non-coding RNA TUG1 affects cell proliferation in human non-small cell lung cancer, partly through epigenetically regulating HOXB7 expression, Cell Death Dis., 5, e1243 (2014).

27. He L, He X, Lim LP, de Stanchina E, Xuan Z, Liang Y, et al., A microRNA component of the $p 53$ tumour suppressor network, Nature, 447, 1130-1134, (2007).

28. Huarte M, Guttman M, Feldser D, Garber M, Koziol MJ, Kenzelmann-Broz D, et al., A large intergenic noncoding RNA induced by $p 53$ mediates global gene repression in the p 53 response, Cell, 142, 409-419 (2010).

29. Hung T, Wang Y, Lin MF, Koegel AK, Kotake Y, Grant GD, et al., Extensive and coordinated transcription of noncoding RNAs within cell-cycle promoters, Nat. Genet., 43, 621-629 (2011).

30. Marín-Béjar O, Marchese FP, Athie A, Sánchez Y, González J, Segura V, et al., Pint lincRNA connects the p53 pathway with epigenetic silencing by the Polycomb repressive complex 2, Genome Biol., 14, R104 (2013).

31. Idogawa M, Ohashi T, Sasaki Y, Nakase H, Tokino T, Long non-coding RNA NEAT1 is a transcriptional target of $p 53$ and modulates $p 53$-induced transactivation and tumor-suppressor function, Int. J. Cancer (2017).

32. Li LH, Tu QY, Deng XH, Xia J, Hou DR, Guo K, et al., Mutant presenilin2 promotes apoptosis through the $p 53 / m i R-34 a$ axis in neuronal cells, Brain Res., [Epub ahead of print] (2017).

33. Kotake Y, Goto T, Naemura M, Inoue Y, Okamoto H, Tahara K, Long Noncoding RNA PANDA Positively Regulates Proliferation of Osteosarcoma Cells, Anticancer Res., 37, 81-85 (2017).

34. He L, He X, Lim LP, de Stanchina E, Xuan Z, Liang Y, et al., A microRNA component of the $p 53$ tumour suppressor network, Nature, 447, 1130-1134 (2007).

35. Huarte M, Guttman M, Feldser D, Garber M, Koziol MJ, Kenzelmann-Broz D, et al., A large intergenic noncoding $R N A$ induced by $p 53$ mediates global gene repression in the $p 53$ response, Cell, 142, 409-419 (2010).

36. Concepcion CP, Han YC, Mu P, Bonetti C, Yao E, D’Andrea A, et al., Intact p53-dependent responses in miR-34-deficient mice, PLoS Genet., 8, e1002797 (2012).

37. Dimitrova N, Zamudio JR, Jong RM, Soukup D, Resnick R, Sarma K, et al., LincRNA-p21 activates $p 21$ in cis to promote polycomb target gene expression and to enforce the G1/S checkpoint, Mol. Cell, 54, 777-790 (2014).

38. Tang SS, Zheng BY, Xiong XD, LincRNA-p21: Implications in human diseases, Int. J. Mol. Sci., 16, 18732-18740 (2015).

39. Fischer M, Steiner L, Engeland K, The transcription factor p53: not a repressor, solely an activator, Cell Cycle, 13, 3037-3058 (2014).

40. Chillon I, Pyle AM, Inverted repeat Alu elements in the human lincRNA-p21 adopt a conserved secondary structure that regulates RNA function, Nucleic Acids Res., 44, $9462-9471$ (2016).

41. Subramaniam D, Thombre R, Dhar A, Anant S, DNA Methyltransferases: A Novel Target for Prevention and Therapy, Front Oncol., 4, 80 (2014)

42. Bao X, Wu H, Zhu X, Guo X, Hutchins AP, Luo Z, et al., The p53-induced lincRNA-p21 derails somatic cell reprogramming by sustaining $\mathrm{H} 3 \mathrm{~K} 9 \mathrm{me} 3$ and $C p \mathrm{G}$ methylation at pluripotency gene promoters, Cell Res., 25, 80-92 (2015).

43. Fletcher Jones M, Lal A, MicroRNAs, wild-type and mutant $p 53$ : More questions than answers, RNA Biology, 6, 781-791 (2012).

44. Kumar M, Lu Z, Takwi AA, Chen W, Callander NS, Ramos KS, et al., Negative regulation of the tumor suppressor $p 53$ gene by microRNAs, Oncogene, 30, 843-853 (2011).

45. Le M, Teh C, Shyh-Chang Ng, Xiel H, Zhou B, Korzh V, et al., MicroRNA-125b is a novel negative regulator of $p 53$, Genes \& Dev., 23, 862-876 (2009).

46. Wang F, Yu D, Liu Z, Wang R, Xu Y, Cui H, MiR-125b Functions as a Tumor Suppressor and Enhances Chemosensitivity to Cisplatin in Osteosarcoma, Technol. Cancer Res. Treat., 6, NP105-NP112 (2016).

47. Hu W, Chan CS, Wu R, Zhang C, Sun Y, Song JS, Negative Regulation of Tumor Suppressor 553 by MicroRNA miR-504, Mol. Cell., 38, 689-699 (2010).

48. Swarbrick A, Woods SL, Shaw A, Balakrishnan A, Phua Y, Nguyen A, et al., miR-380-5p represses $p 53$ to control cellular survival and is associated with poor outcome in MYCN-amplified neuroblastoma, Nat. Med., 16, 1134-1140 (2010).

49. Ouyang Z, Zheng G and Chang HY, Noncoding RNA landmarks of pluripotency and reprogramming, Cell Stem Cell. 7, 649-650 (2010).

50. Herrero AB, Rojas EA, Misiewicz-Krzeminska I, Krzeminski P, Gutiérrez NC, Molecular Mechanisms of $p 53$ Deregulation in Cancer: An Overview in Multiple Myeloma,

Int. J. Mol. Sci., 17, E2003 (2016). 
51. Tian S, Huang S, Wu S, Guo W, Li J, He X, MicroRNA-1285 inhibits the expression of $p 53$ by directly targeting its 3' untranslated region, Biochem. Biophys. Res. Commun., 396, 435-439 (2010).

52. Becker LE, Takwi A, Lu Z and Li Y, The role of miR-200a in mammalian epithelial cell transformation, Carcinogenesis, 36, 2-12 (2015).

53. Fabbri M, Bottoni A, Shimizu M, Spizzo R, Nicoloso MS, Rossi S, et al., Association of a MicroRNA/TP53 Feedback Circuitry with Pathogenesis and Outcome of B-Cell Chronic Lymphocytic Leukemia, JAMA, 305, 59-67 (2011).

54. Zhang C, Liu C, Wang X and Feng Z, The regulation of the $p 53 /$ MDM2 feedback loop by microRNAs, RNA Dis., 2, 1 (2015).

55. Lou G, Liu Y, Wu S, Xue J, Yang F, Fu H, et al., The p53/miR-34a/SIRT1 Positive Feedback Loop in Quercetin-Induced Apoptosis, Cell Physiol. Biochem., 35, 2192-2202 (2015).

56. Borzi C, Calzolari L, Centonze G, Milione M, Sozzi G,
Fortunato O, mir-660-p53-mir-486 Network: A New Key Regulatory Pathway in Lung Tumorigenesis,

Int. J. Mol. Sci., 18, 222 (2017).

57. Krell J, Frampton AE, Colombo T, Gall T, De Giorgio A, Harding V, et al., The p53 miRNA interactome and its potential role in the cancer clinic, Epigenomics, 5, 417-428 (2013).

58. Yoshiki Murakami Y, Kawada N, MicroRNAs in hepatic pathophysiology, Hepatol. Res., 47, 60-69 (2017).

59. Feng Z, Zhang C, Wu R, Hu W, Tumor suppressor $p 53$ meets microRNAs, J. Mol. Cell. Biol., 3, 44-50 (2011).

60. Mak C, Yung M, Hui L, Leung L, Liang R, Chen K, et al., MicroRNA-141 enhances anoikis resistance in metastatic progression of ovarian cancer through targeting KLF12/Sp1/survivin axis, Mol. Cancer, 16, 11 (2017).

61. Li J, Xia W, Su X, Qin X, Chen Y, Li S, et al., Species-specific mutual regulation of $p 53$ and miR-138 between human, rat and mouse, Sci. Rep., 6 (2016). 